\title{
An Assessment of the ANV 20/20 Focusing Aid for Night Vision Devices
}

\author{
Maj AG Manton \\ $M B, C h B, R A M C$ \\ Trainee Specialist in Aviation Medicine
}

Department of Aviation Medicine, School of Army Aviation, Middle Wallop, Stockbridge, Hants SO20 8DY

WO2 KW Webster, AAC

$\mathrm{QHI}$

Development and Trials Squadron, School of Army Aviation, Middle Wallop, Stockbridge, Hants SO20 8DY

SUMMARY: Night vision goggles (NVGs) are becoming an increasingly important tool in military aviation. They provide superior visual capability over unaided night vision, but any reduction in goggle performance can have a serious effect on flight safety and operational effectiveness. This study shows that the use of the ANV $20 / 20$ focusing aid provides an effective method for aircrew to obtain a better visual capability than is currently obtained by focusing on distant features of the landscape or distant lights. Visual acuities using the current and proposed focus- $\vec{f}$ ing methods were compared in 50 aircrew. The visual acuity showed an average improvement of $18 \%$ with the proposed method compared with the current method. This was found to be statistically significant (p<0.01). Using the current method of focusing there was a significant $(p<0.01)$ difference in the visual acuity achieved between the 8 right and left tubes/eyes. Using the ANV 20/20 there was no difference between tubes/eyes. ANV 20/20 was found to $ᄋ$ improve visual acuity when using NVG as well as enabling the user to achieve equal visual acuities with both eye

\section{Introduction}

Night operations are playing an increasing role in military operations. NVGs are widely used to enhance visual capabilities at night and as such have become an essential component of military aviation (1). They provide an amplified image of the ambient light, and although this is superior to unaided night vision, it is still inferior to daylight vision (2).

NVGs are a binocular assembly of two image intensifier tubes. Each of these has an objective lens which focuses an image onto a photo-cathode. A microchannel plate then amplifies the image onto a phosphor screen which is then viewed through the eyepiece (dioptre) lens (3). ANVIS types goggles are designed in such a way that the objective and eyepiece lenses can be adjusted (Fig 1). NVGs are a valuable aid to night flight, but they have inherent limitations. These limitations can be split into three groups: visual limitations and spatial disorientation (related to field of view, visual contrast and acuity); crew performance (affected by fatigue, endurance and crew coordination); and systems/hardware problems such as the inability to see wires and dimming of the image (by automatic gain control) due to bright lights (4).

Student pilots at the School of Army Aviation are given instruction on the use of NVGs as well as a briefing from a specialist in Aviation Medicine on the medical aspects of night vision and NVGs. They undergo 8 hours in flight training with goggles during the Army pilot course. As part of their training they are taught how to focus and adjust the goggles prior to flying. Observations of the preflight routines of Army Air Corps pilots revealed that preflight adjustment and focusing procedures could be
The binocular assembly contains the optical elements of the system. This component has several adjustment feature Learning to operate each feature is essential for propef alignment of the device. The following is a list of adjustment features on the binocular assembly:

a. Fore and aft adjustment knob - moves the entire binocula assembly toward or away from the eyes.

b. Tilt adjustment knob - allows wearer to rotate tie binocular assembly.

c. Interpupillary distance (eyespan) adjustment knob - allows wearer to adjust for the distance between the eyes.

d. Objective focus ring - focuses the goggles for distance (adjustment range is from 10 inches to infinity).

e. Diopter focus ring - compensates for individual refractive error.

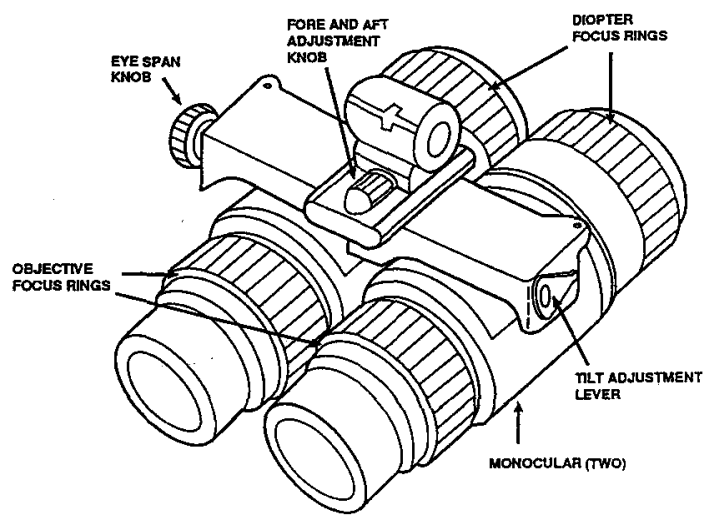

Fig 1. The binocular assembly

improved. The present method can give errors which are enough to cause a significant reduction in visual acuity ${ }_{\sigma}^{\omega}$ (5). 


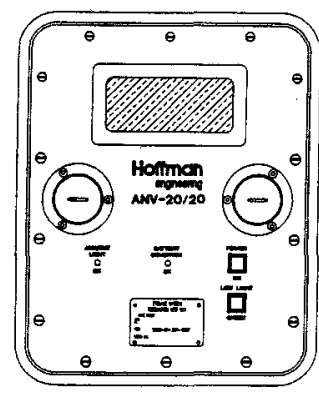

SPECIFICATIONS:

\section{MECHANICAL:}

Case Size (w/cover)

Case Size (w/out cover)

Test Set Weight (w/batteries)

\section{ELECTRICAL:}

\section{Power Source}

Battery Life (normal mode)

Battery Replacement Limit Ambient Light Sensor Ambient Light Level Limit
$13 \mathrm{H} \times 10.5 \mathrm{~W} \times 9.6 \mathrm{D}$ (inches) $13 \mathrm{H} \times 10.5 \mathrm{~W} \times 6.2 \mathrm{D}$ (inches) 26lbs (MIL-SPEC),

23lbs (Non MIL-SPEC)

Four D size Alkaline Batteries 1500 cycles (minimum), 3 minute cycle $<1.05 \mathrm{~V}$

Silicon Photodiode $<0.1 \mathrm{fC}$

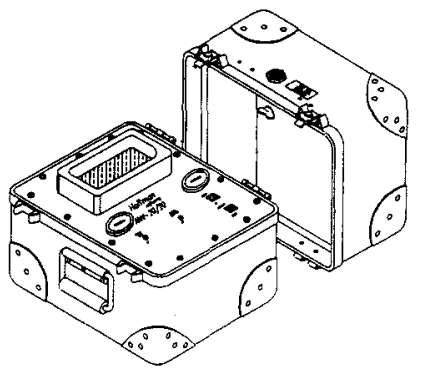

OPTICAL:

Light Source

Focal Settings

Reticle Resolution

Reticle Luminance

Source Accuracy

Left/Right Collimation

System MTF
LED, Continuously Monitored 100 Meters (minimum), Infinity (maximum)

0.49 to 1.72 Line Pairs per milliradian

Approx 1/4 Moon-Normal, Starlight-Low $+/-5 \%$ at Normal Mode $<0.5$ degree error $>75 \%$

Fig 2. ANV-20/20 NVD Infinity Focus

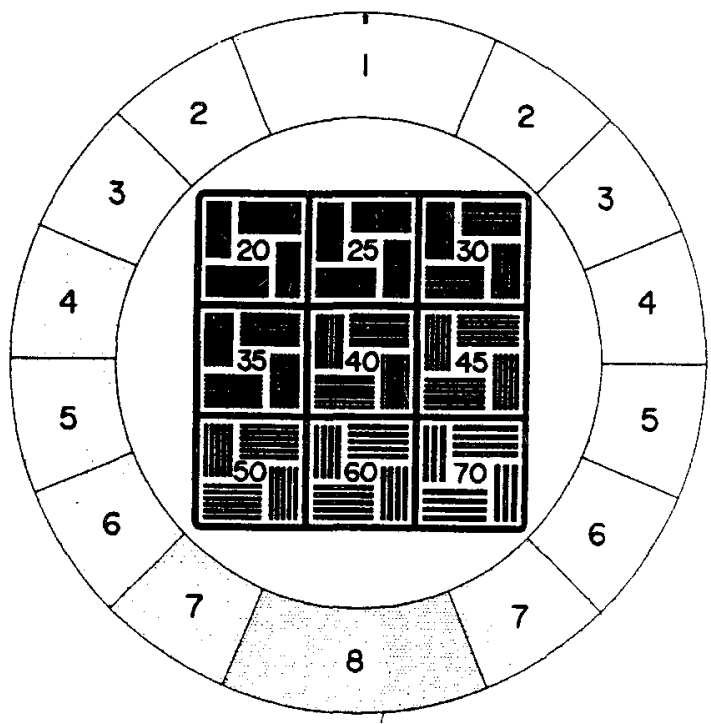

Fig 3. Reticle Pattern
Common methods currently used to focus and adjus NVGs include focusing on a nearby hill or othe landscape features around the airfield. In-flight adjustment of goggles is often found to be necessary, and qualified helicopter instructors (QHI) were often unsure of the visual acuity levels achieved by their students.

The use of the ANV 20/20 provides a method of accurately focusing all types of NVGs and provides the goggle user with a standard measure of his (and his/her students) goggle performance. It also allows the NVG novice to learn what should be seen through the goggles when they are properly adjusted and focused. This device can also be used when goggle adjustment 'in the field' is necessary. It is hoped that deterioration in tube performance will be noticed earlier than with current routines used, allowing defective tubes to be replaced before problems are noted in flight.

The ANV 20/20 is a compact portable system designed to provide the NVG user with an accurate means of performing infinity focus and mechanical alignment, Fig 2.

The system presents a resolution pattern at infinity focus to both NVG tubes. This allows proper adjustment to be done quickly. The resolution pattern is directly correlated to the Snellen Eye Chart providing a visual acuity range of $20 / 20$ to $20 / 70$.

The reticle pattern seen by the NVG user can be seen at 
Table 1

Visual acuity using each tube independently after the subject had focused the goggles by his/her usual method

\begin{tabular}{|c|c|c|c|c|c|}
\hline CREW POSITION & $\begin{array}{l}\text { FLYING HOURS } \\
\text { ON NVG }\end{array}$ & $\begin{array}{l}\text { RIGHT V/A WITH } \\
\text { CURRENT METHOD }\end{array}$ & $\begin{array}{c}\text { LEFT V/A WITH } \\
\text { CURRENT METHOD }\end{array}$ & $\begin{array}{c}\text { RIGHT V/A WITH } \\
\text { ANV 20/20 }\end{array}$ & $\begin{array}{c}\text { LEFT V/A WITH } \\
\text { ANV 20/20 }\end{array}$ \\
\hline Instructor & 100 & 50 & 45 & 40 & 40 \\
\hline$\overline{\text { Student }}$ & 0 & 50 & 70 & 40 & 40 \\
\hline Student & 5 & 60 & 70 & 30 & 35 \\
\hline Student & 0 & 45 & 70 & 40 & 50 \\
\hline Student & 4 & 50 & 45 & 50 & 45 \\
\hline Instructor & 70 & 60 & 50 & $\overline{45}$ & 35 \\
\hline Student & 4 & 40 & 45 & 35 & 45 \\
\hline Student & 4 & 40 & 45 & 40 & 40 \\
\hline Instructor & 150 & 60 & 60 & 45 & $\overline{35}$ \\
\hline Instructor & 60 & 50 & 50 & 45 & 35 \\
\hline Student & 20 & 70 & 70 & 70 & 70 \\
\hline Student & 4 & 70 & 40 & 45 & 40 \\
\hline Student & 5 & 70 & 45 & 40 & 45 \\
\hline Instructor & 230 & 40 & 45 & 40 & 45 \\
\hline Student & 5 & 20 & 40 & 40 & 40 \\
\hline Student & 0 & 40 & 50 & 35 & 45 \\
\hline Student & 0 & 45 & 45 & 40 & 40 \\
\hline Student & 0 & 50 & 70 & 40 & 40 \\
\hline Student & 0 & 60 & 60 & 50 & $\overline{45}$ \\
\hline Instructor & 80 & 40 & 45 & 35 & 35 \\
\hline Student & 3 & 45 & 50 & 45 & 45 \\
\hline Student & 4 & 70 & 70 & 40 & 40 \\
\hline Instructor & 220 & 40 & 35 & 40 & 35 \\
\hline Instructor & 230 & 35 & 70 & 35 & 45 \\
\hline Instructor & 9 & 50 & 60 & 45 & 45 \\
\hline Pilot & 40 & 50 & 70 & 45 & 45 \\
\hline Pilot & 120 & 50 & 40 & 40 & 40 \\
\hline Pilot & 90 & 70 & 60 & 45 & 45 \\
\hline Pilot & 100 & 40 & 35 & 35 & 35 \\
\hline Pilot & 90 & 35 & 40 & 35 & $\overline{40}$ \\
\hline Pilot & 50 & 40 & 45 & 35 & 40 \\
\hline Pilot & 200 & 40 & 40 & 35 & 30 \\
\hline Pilot & 18 & 60 & 60 & 45 & 40 \\
\hline Pilot & 40 & 50 & 70 & 45 & 45 \\
\hline$\overline{\text { Pilot }}$ & 10 & 35 & 60 & 35 & 45 \\
\hline$\overline{\text { Pilot }}$ & 30 & 45 & 45 & 40 & $\overline{40}$ \\
\hline Pilot & 350 & 40 & 45 & 40 & 45 \\
\hline Pilot & 50 & 40 & 45 & 40 & 45 \\
\hline Pilot & 30 & 40 & 60 & 35 & 45 \\
\hline Pilot & 160 & 50 & 60 & 30 & 35 \\
\hline$\overline{\text { Pilot }}$ & 30 & 50 & 40 & 35 & 35 \\
\hline Pilot & 17 & 40 & 40 & 35 & 35 \\
\hline Pilot & 30 & 50 & 70 & 35 & 40 \\
\hline Pilot & 95 & 40 & 45 & 40 & 45 \\
\hline Pilot & 8 & 35 & 45 & 35 & 40 \\
\hline Pilot & 40 & 60 & 60 & 40 & 40 \\
\hline Pilot & 95 & 40 & 45 & 40 & 45 \\
\hline Pilot & 70 & 30 & 45 & 30 & 35 \\
\hline$\overline{\text { Pilot }}$ & 15 & 45 & 35 & 40 & $\overline{35}$ \\
\hline Instructor & 800 & 40 & 40 & 35 & 35 \\
\hline
\end{tabular}


Fig 3. It should be noted that the numbers seen in the centre grids correlate with the American 20/20 Snellen scale for visual acuity.

\section{Subjects}

Data were collected at the School of Army Aviation (a training environment) and in Northern Ireland (an operational environment). Fifty helicopter aircrew were studied, 10 qualified helicopter instructors, 24 helicopter pilots and 16 student pilots. All of the subjects had undergone ground-based NVG training and the NVG experience ranged from 0 to $800 \mathrm{NVG}$ flying hours.

\section{Method}

The ANV 20/20 is a focusing aid, not a direct measurer of visual acuity. It was felt however, that a comparison could be made between acuities achieved using the current focusing technique, and those achieved using the ANV 20/20.

Visual acuity was 'measured' using each tube independently after the subject had focused the goggles by his/her usual method. The subject was asked to look at the reticle image and note the lowest number around which they could differentiate between the horizontal and vertical lines. They were then asked to refocus the tube being measured, using the reticle pattern as a focusing aid. Again the lowest number around which the horizontal and vertical lines could be differentiated between was noted.

The tube not in use was covered with a lens cap, to avoid the subject having to close one eye. The 'starting' visual acuity (i.e: without NVG) of each subject was $20 / 20$ or better, corrected where necessary with flying spectacles.

\section{Results}

The results can be seen in Table 1 . The numbers represent the bottom figure of the 20/20 Snellen Fraction. There was a mean improvement in visual acuity from $20 / 49.4$ to $20 / 40.5$. By using the Bonferron test this was found to be statistically significant, $\mathrm{p}<0.01$.

The test also showed that using the current method, visual acuities achieved with the right eye (and tube) were better than those achieved with the left eye (and tube), $\mathrm{p}<0.01$. However, using the ANV 20/20 there is no significant difference between the two eyes (and tubes).

\section{Discussion}

The use of the ANV 20/20 for focusing results in better visual acuity than using the current techniques of focusing. This indicates better visual performance and should lead to a greater operational effectiveness and safety during night missions. This may also help alleviate visual fatigue problems, caused by poor focusing and misalignment of goggles.

It was found that the visual acuity of the right eye was superior to that of the left eye when using the current method of NVG adjustment. Even slight differences in focus between the eyes are thought to result in visual fatigue and this observation may explain some of the current problems of headaches and visual discomfort currently being experienced by aircrew after NVG sorties $(5,6)$. This is the subject of ongoing research at the School of Army Aviation. Using the ANV 20/20, no significant differences in the visual acuity were found between the eyes. Unlike previous standardised focusing techniques studies (5), the ANV 20/20 is a truly portable device. It is light (26lbs), and travels in a robust box, and is battery operated. Presenting the user with an image at infinity means that no further adjustment of the goggles is necessary before flying. The NVG does not have to be mounted or attached to the unit. The user simply looks into the unit and focuses. This means that the ANV 20/20 can be used with all types of NVG currently used by the Army Air Corps.

Although the goggles need to be focused in darkness using the ANV 20/20, it is not essential to have a completely light tight room. This makes it a more practical tool for operational use.

\section{Acknowledgements}

This study could not have been conducted without the assistance of 670 Sqn and 5 Regt, Army Air Corps. Mang thanks to all those who took part. Also many thanks to De Andy Belyavin for his help in statistically analysing the data.

\section{REFERENCES}

1. BEKLEY WE. Night Operations. AGARD LS-187: Visual problems in night operations. 1992:1.1-1.4.

2. НІскок SM. Night Vision goggle training in the US coast guard. Aeromed Train Dig 1992 Vol 6 Issue 2.

3. MILLER RE, TREDICI TJ. Introduction to night vision goggles. Night Visual Manual for the Flight Surgeon, Ch 4. AL-SR-1992-0002. Armstrong Laboratory. Brookes AFB, TX.

4. COGHLAN HA. Living with NVG. Defence Helicopter July-Sept. 1992:47-50.

5. MAnton AG. An assessment of a proposed method for adjusting and focusing ANVIS night vision goggles. JR Army Med Corps 1996; 142: 20-23.

6. Fowlkes JE, Kennedy, HetTinger LJ, Horm DL. Changes in the dark focus of accommodation associated with simulator sickness. Aviat Space Environ Med. 1993; 64: 612-8. 